\title{
Swallowable capsules are not only for videos
}

\section{(ㄷ)(i)}

\author{
Author \\ Carolina Olano \\ Institution \\ Hospital de Clínicas, Montevideo, Uruguay \\ Bibliography \\ DOI https://doi.org/10.1055/a-0884-2992 | \\ Endoscopy International Open 2019; 07: E782-E783 \\ (c) Georg Thieme Verlag KG Stuttgart · New York \\ eISSN 2196-9736
}

\author{
Corresponding author \\ Carolina Olano, Hospital de Clínicas, Av. Italia S/n CP, 11600 \\ Montevideo, Uruguay \\ Fax: +598-2-4872572 \\ carolinaolanouruguay@gmail.com
}

Originally thought to be a tribute to the spirit of the novels of Jules Verne, "Fantastic Voyage" (20th Century Fox, directed by Richard Fleischer, 1966) is one of those memorable films. In it, a shrunken submarine is injected into a scientist's body so the crew can operate on his brain. This might have been science fiction at that time, but nowadays it is becoming reality! According to the report by "Markets \& Markets", the Smart pills business is forecast to reach $\$ 3.83$ billion in 2020 , growing to reach $\$ 8.98$ billion by 2024 [1].

Owing to the capacity of the gastrointestinal tract to tolerate a range of materials and objects, swallowable cameras the size of a large pill were designed at first, to take pictures of the esophagus, small bowel, and colon in a non-invasive way [2,3]. The launch of the first videocapsule endoscopy (PillCam, Medtronic, Minneapolis, MN, United States) in 2001 revolutionized the endoscopy market and since then, several companies have sold millions of these devices around the World. Many algorithms, modules and integrated systems have been devised to enable and enhance the diagnostic and even robotic capabilities of capsules working within the gastrointestinal tract [2, $4-7]$.

Consequently, these swallowable devices can do much more than just snap pictures. The gut provides easy and rapid access for biomarker and microbiota chemical by-products and it is possible for capsules to carry a wide range of biosensors onboard to measure various physical, chemical and physiological parameters such as $\mathrm{pH}$, pressure, oxygenation, impedance (electrical conductivity), temperature, intraluminal gas, and to detect blood $[2,8]$. Wireless telemetry is the remote monitoring of patients' physiological parameters over a distance via radiofrequency communications between a transmitter worn by the patient and a central monitoring station [8]. This technology is used in the new generation of capsules beyond just providing images.
One example of this is the Wireless Motility and $\mathrm{pH}$ Monitoring System (WMC) which possesses sensors that continuously monitor the temperature, $\mathrm{pH}$, and pressure of its immediate surrounds $[9,10]$. From this information, a precise determination of gastric emptying time (GET), small-bowel transit time (SBTT), and colon transit time (CTT) can be made $[9,10]$.

The WMC has been approved by the US Food and Drug Administration (FDA) for the evaluation of suspected conditions such as delayed gastric emptying and for the evaluation of coIonic transit in chronic idiopathic constipation. In a position paper published in 2011, the American and European Neurogastroenterology and Motility Societies (ANMS and ESNM) have outlined the clinical indications for using the WMC [11]. These indications include: (1) the assessment of gastric emptying in suspected cases of gastroparesis and symptoms of upper gastrointestinal dysmotility; (2) the assessment of small-bowel transit to specifically facilitate the detection of small-bowel dysfunction in more generalized gastrointestinal motility disorders; and (3) the assessment of colonic transit time in cases of chronic constipation [11]. A systematic review assessed the comparative effectiveness of WMC with other tests of gastric and colonic motility [12].

Another example of the use of Wireless Telemetry is presented in the study by Dr. Arthur Schmidt et al. from the Medical Center of Ludwigsburg and University of Tübingen, Germany [13]. In this pilot study, the feasibility and safety of the detection of acute upper gastrointestinal bleeding were evaluated using a novel telemetric sensor capsule. This is a diagnostic capsule equipped with a sensor for in vivo detection of liquid blood or hematin that contains a measuring slot for blood entry. When the capsule is activated, red and violet light is emitted by LEDs. Owing to its distinctive optical properties, the presence of blood can be predicted. This prospective clinical trial included consecutive, stable patients with hematemesis, coffee-ground emesis or melena from the emergency depart- 
ment. Patients with known or suspected stenosis of the gastrointestinal tract, variceal bleeding, swallowing disorders, pregnancy, patients younger than 18 years or older than 80 years were excluded. Each patient received upper endoscopy within 12 hours after capsule to verify the bleeding and its source.

Despite the low number of patients, the authors found that the sensor capsule was safe as no device-related adverse events occurred. From all patients with positive endoscopies for any possible cause of gastrointestinal bleeding, only $30 \%$ had positive sensor capsules. However, this percentage climbed to $100 \%$ in patients with estimated "intense" bleeding, which was defined as more than $20 \mathrm{~mL}$ of blood within the stomach. Therefore, the telemetric sensor capsule would be a good triage tool to decide which patients would require urgent endoscopic treatment, as endoscopy would be futile in patients with a small amount of blood (i. e. $<20 \mathrm{~mL}$ ) inside the upper gastrointestinal tract. Reassuringly, the sensor capsule was negative in all cases of negative endoscopy. Larger studies are necessary to further determine the negative predictive value to identify patients not requiring urgent endoscopy.

This paper is of value as it is the first clinical trial with an exploratory purpose in a real setting after two preclinical studies in a porcine model and a study on human volunteers with a similar device presented by other colleagues [14-16]. As limitations of the study, besides the low number of patients, the heterogeneous interval between ingestion of the sensor capsule and the gold standard (upper endoscopy) must be considered to be a source of bias. Nonetheless, the study results are very promising and should encourage further prospective, larger multicenter trials.

Swallowable devices continue to appear in the market day by day: medication monitoring pills, advanced drug-delivery devices, and capsules with an integrated transducer for ultrasound imaging, among others [2,17-19]. In the future, the abilities of capsule endoscopy will increase and their size will decrease such that their use in smaller areas of the human body beyond the gastrointestinal tract, will become feasible [20]. Capsule endoscopy promises inexpensive and painless surgery without the use of anesthesia [20]. The future of medical diagnosis and treatment using these tiny devices is promising and not even Jules Verne and his fanciful thought could have imagined all this.

\section{Competing interests}

\section{None}

\section{References}

[1] Smart Pills Market by Application (Capsule Endoscopy, Drug Delivery, Patient Monitoring), Target Area (Esophagus, Stomach, Small Intestine, Large Intestine), Geography - Global Forecast to 2024. 2018: Available at: https://www.marketsandmarkets.com/PressReleases/ smart-pill.asp
[2] Kalantar-Zadeh K, Ha N, Ou JZ et al. Ingestible sensors. ACS Sens 2017; 2: $468-483$

[3] Neumann H, Fry LC, Neurath MF. Review article on current applications and future concepts of capsule endoscopy. Digestion 2013; 87: 91-99

[4] Ogata N, Ohtsuka K, Sasanuma S et al. White light-emitting contrast image capsule endoscopy for visualization of small intestine lesions: a pilot study. Endosc Int Open 2018; 6: E315-E321

[5] Koulaouzidis A, lakovidis DK, Yung DE et al. Novel experimental and software methods for image reconstruction and localization in capsule endoscopy. Endosc Int Open 2018; 6: E205 - E210

[6] Hosoe N, Watanabe K, Miyazaki T et al. Evaluation of performance of the Omni mode for detecting video capsule endoscopy images: A multicenter randomized controlled trial. Endosc Int Open 2016; 4: $\mathrm{E} 878-\mathrm{E} 882$

[7] Hale MF, Drew K, Sidhu R et al. Does magnetically assisted capsule endoscopy improve small bowel capsule endoscopy completion rate? A randomised controlled trial Endosc Int Open 2016; 4: E215-E221

[8] Toennies JL, Tortora G, Simi M et al. Swallowable medical devices for diagnosis and surgery: the state of the art. Proc Inst Mech E (C) J Mech Eng Sci 2010; 224: 1397 - 1414

[9] Sarosiek I, Semler JR, McCallum RW et al. New methodology in assessing gastric emptying and gastrointestinal transit. US Gastroenterol Rev 2007; 1: 19-22

[10] Saad R. The Wireless Motility Capsule: a one-stop shop for the evaluation of GI motility disorders. Curr Gastroenterol Rep 2016; 18: 14 21

[11] Rao SS, Camilleri M, Hasler WL et al. Evaluation of gastrointestinal transit in clinical practice: position paper of the American and European Neurogastroenterology and Motility Societies. Neurogastroenterol Motil 2011; 23: 8-23

[12] Stein E, Berger Z, Hutfless S et al. Wireless Motility Capsule versus other diagnostic technologies for evaluating gastroparesis and constipation: A comparative effectiveness review [Internet]. Rockville (MD): Agency for Healthcare Research and Quality (US); 2013 May. Report No.: 13-EHC060-EF

[13] Schmidt A, Zimmermann M, Bauder M et al. Novel telemetric sensor capsule for EGD urgency triage: a feasibility study. Endosc Int Open 2019; 07: E774-E781

[14] Schostek S, Zimmermann M, Keller ] et al. Telemetric real-time sensor for the detection of acute upper gastrointestinal bleeding. Biosens Bioelectron 2016; 78: 524-529

[15] Schostek S, Zimmermann M, Keller J et al. Volunteer case series of a new telemetric sensor for blood detection in the upper gastrointestinal tract: The HemoPill. Dig Dis Sci 2016; 61: 2956-2962

[16] Qiao PP, Liu HY, Yan XP et al. A smart capsule system for automated detection of intestinal bleeding using HSL color recognition. PloS One 2016; 11: e0166488

[17] Bettinger C]. Materials advances for next-generation ingestible electronic medical devices. Trends Biotechnol 2015; 33: 575-585

[18] Ciuti G, Menciassi A, Dario P. Capsule endoscopy: from current achievements to open challenges. IEEE Rev Biomed Eng 2011; 4: 59 72

[19] Lay HS, Qiu Y, Al-Rawhani M et al. Progress towards a multi-modal capsule endoscopy device featuring microultrasound imaging. In 2016 IEEE International Ultrasonics Symposium 2016: 16429247

[20] Intzes I, Meng H, Cosmas ]. Technology of swallowable capsule for medical applications. Int J Biomed Eng Technol 2014; 14: 277 - 296 